\title{
Effect of Bonding Strength on Electromigration Failure in Cu-Cu Bumps
}

\author{
Kai-Cheng Shie ${ }^{1,2}$, Po-Ning Hsu ${ }^{1,2}$, Yu-Jin Li ${ }^{1,2}$, K. N. Tu ${ }^{1,2,3,4}$ and Chih Chen ${ }^{1,2, *(1)}$ \\ 1 Department of Materials Science and Engineering, National Yang Ming Chiao Tung University, \\ Hsinchu 30010, Taiwan; alex911666.mse06g@g2.nctu.edu.tw (K.-C.S.); \\ seraph8938.mse03g@g2.nctu.edu.tw (P.-N.H.); a0481518.mse04g@g2.nctu.edu.tw (Y.-J.L.); \\ kntu@ucla.edu (K.N.T.) \\ 2 Department of Materials Science and Engineering, National Chiao Tung University, Hsinchu 30010, Taiwan \\ 3 International College of Semiconductor Technology, National Yang Ming Chiao Tung University, \\ Hsinchu 30010, Taiwan \\ 4 International College of Semiconductor Technology, National Chiao Tung University, Hsinchu 30010, Taiwan \\ * Correspondence: chih@mail.nctu.edu.tw; Tel.: +886-3-5731814; Fax: +886-3-5724727
}

Citation: Shie, K.-C.; Hsu, P.-N.; Li, Y.-J.; Tu, K.N.; Chen, C. Effect of Bonding Strength on Electromigration Failure in $\mathrm{Cu}-\mathrm{Cu}$ Bumps. Materials 2021, 14, 6394. https://doi.org/10.3390/ma14216394

Academic Editor: Filippo Berto

Received: 16 September 2021

Accepted: 20 October 2021

Published: 25 October 2021

Publisher's Note: MDPI stays neutral with regard to jurisdictional claims in published maps and institutional affiliations.

Copyright: (C) 2021 by the authors. Licensee MDPI, Basel, Switzerland. This article is an open access article distributed under the terms and conditions of the Creative Commons Attribution (CC BY) license (https:/ / creativecommons.org/licenses/by/ $4.0 /)$.
Abstract: In microelectronic packaging technology for three-dimensional integrated circuits (3D ICs), $\mathrm{Cu}$-to-Cu direct bonding appears to be the solution to solve the problems of Joule heating and electromigration (EM) in solder microbumps under $10 \mu \mathrm{m}$ in diameter. However, EM will occur in $\mathrm{Cu}-\mathrm{Cu}$ bumps when the current density is over $10^{6} \mathrm{~A} / \mathrm{cm}^{2}$. The surface, grain boundary, and the interface between the $\mathrm{Cu}$ and TiW adhesion layer are the three major diffusion paths in EM tests, and which one may lead to early failure is of interest. This study showed that bonding strength affects the outcome. First, if the bonding strength is not strong enough to sustain the thermal mismatch of materials during EM tests, the bonding interface will fracture and lead to an open circuit of early failure. Second, if the bonding strength can sustain the bonding structure, voids will form at the passivation contact area between the $\mathrm{Cu}-\mathrm{Cu}$ bump and redistribution layer (RDL) due to current crowding. When the void grows along the passivation interface and separates the $\mathrm{Cu}-\mathrm{Cu}$ bump and RDL, an open circuit can occur, especially when the current density and temperature are severe. Third, under excellent bonding, when the voids at the contact area between the $\mathrm{Cu}-\mathrm{Cu}$ bump and RDL do not merge together, the EM lifetime can be more than $5000 \mathrm{~h}$.

Keywords: electromigration; $\mathrm{Cu}-\mathrm{Cu}$ direct bonding; three-dimensional integrated circuits (3D ICs)

\section{Introduction}

Due to the ending of Moore's law on the miniaturization of two-dimensional integrated circuits (2D IC), 3D ICs through chip stacking technology is the most promising way to continuously improve the chip performance [1-3]. In 3D ICs, because there are many reliability issues in shrinking solder joints [4-10], Cu-to-Cu direct bonding technology has been introduced to scale down the diameter of joints [11-14]. Below, we shall use $\mathrm{Cu}-\mathrm{Cu}$ to represent $\mathrm{Cu}$-to- $\mathrm{Cu}$.

On $\mathrm{Cu}-\mathrm{Cu}$ direct bonding, a low thermal budget in lowering the bonding temperature to $250{ }^{\circ} \mathrm{C}$ and bonding time to $1 \mathrm{~min}$ are the key requirements to be adopted in advanced electronic packaging for high-density interconnects $(<10 \mu \mathrm{m}$ bump diameter) [15-20]. However, with the high current stressing in $\mathrm{Cu}-\mathrm{Cu}$ interconnects, EM takes place again in interconnects, as well as in lines of the redistribution layer (RDL) [21-24].

The EM damages of $\mathrm{Cu}-\mathrm{Cu}$ interconnects include void formation at $\mathrm{Cu} / \mathrm{SiO}_{2}$ and $\mathrm{Cu}$ /adhesion layer interfaces and $\mathrm{Cu}-\mathrm{Cu}$ bonding interfaces $[22,25]$. The reason of void formation at interfaces can be referred from the EM of Cu damascene structures [26-30], but voids at the bonding interface have not been well discussed. Although there have been previous studies of EM in $\mathrm{Cu}-\mathrm{Cu}$ interconnects [22], the effect of bonding strength has not been mentioned. 
In this study, $\mathrm{Cu}-\mathrm{Cu}$ direct bonding microbumps were fabricated [18] to perform EM tests. The bonding strength was measured by the die pull test, as well as by varying the pressure and time in thermal compression bonding. Void formation was studied by both destructive and nondestructive observations. Finite element analysis (FEA) was adopted to realize the current density and stress distribution. According to these analysis results, EM failure mechanisms of $\mathrm{Cu}-\mathrm{Cu}$ bumps can be systemically studied.

\section{Materials and Methods}

\subsection{Sample Fabrication}

The sample for the EM test is shown in Figure 1. A top die was bonded to a bottom die through instant $\mathrm{Cu}-\mathrm{Cu}$ direct bonding $[18,31]$. The method of electroplating nanotwinned $\mathrm{Cu}$ (nt-Cu) [32,33] was adopted to fabricate nt-Cu microbumps because nt-Cu columnar grains have a (111) surface for low-thermal-budget bonding [15] and good mechanical properties [34-37]. However, the structure of passivation (PSV) opening led to some randomness of nt-Cu columnar grains. More sample fabrication details are in Reference [18]. In this study, the bonding temperature was $300^{\circ} \mathrm{C}$. The two conditions of bonding pressure and time were $90 \mathrm{MPa} / 30 \mathrm{~s}$ and $31 \mathrm{MPa} / 10 \mathrm{~s}$.

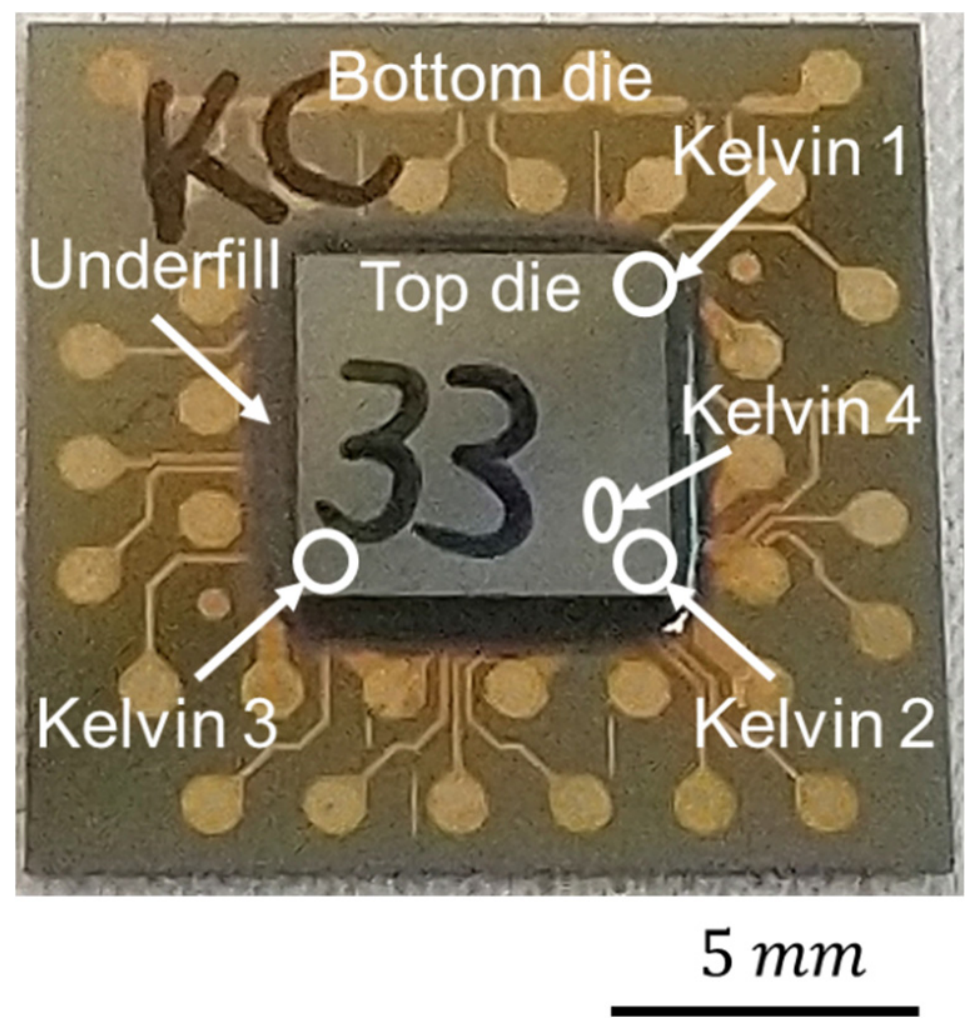

Figure 1. The test vehicle of $\mathrm{Cu}-\mathrm{Cu}$ direct bonding and EM test. After the bonding process, underfill was dispensed into the chip. The sites of electrical test structures are marked on the chip.

The cross-sectional images of two types of $\mathrm{Cu}-\mathrm{Cu}$ bumps are shown in Figure 2. The top and the bottom die RDLs connect with a $\mathrm{Cu}-\mathrm{Cu}$ bump, and the adhesion layer of TiW between them is pointed out by the yellow dashed lines in Figure 2a,c. The photosensitive polybenzoxazole (PBO) cover on the RDLs serves as a passivation layer. A PSV opening was performed through lithography to define the pattern of $\mathrm{Cu}-\mathrm{Cu}$ bumps. In order to protect the $\mathrm{Cu}-\mathrm{Cu}$ bumps from oxidation, underfill (UF) was dispensed in the chip, which can be seen around the top die in Figure 1, and was filled well around $\mathrm{Cu}-\mathrm{Cu}$ bumps in Figure 2a,c. 


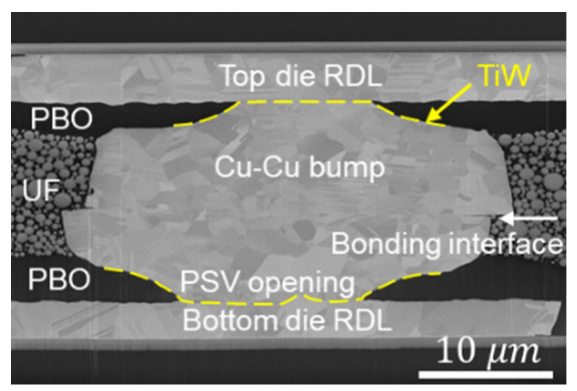

(a)

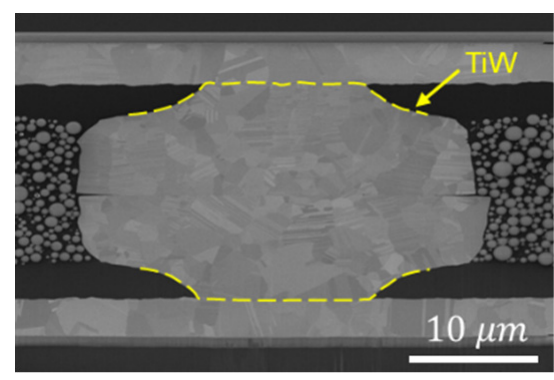

(c)

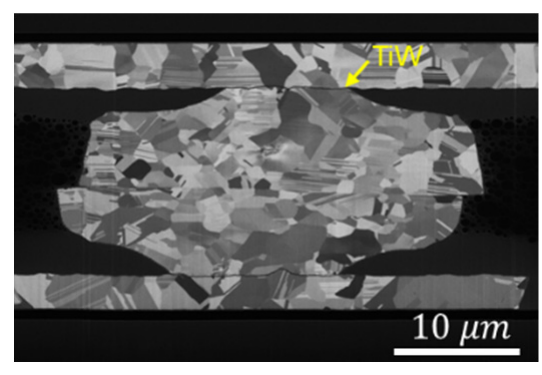

(b)

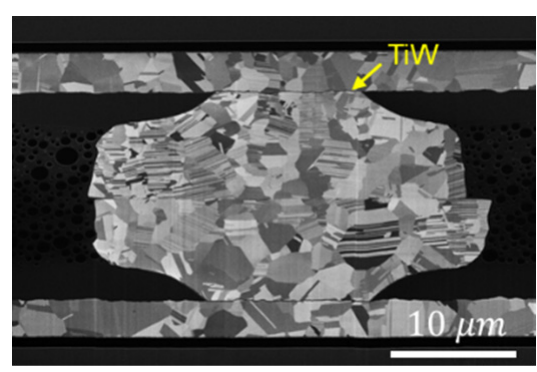

(d)

Figure 2. The cross-sectional images of as-fabricated $\mathrm{Cu}-\mathrm{Cu}$ bumps. (a) Electron image and (b) ion image of $300{ }^{\circ} \mathrm{C} / 90 \mathrm{MPa} / 30 \mathrm{~s}$. (c) Electron image and (d) ion image of $300^{\circ} \mathrm{C} / 31 \mathrm{MPa} / 10 \mathrm{~s}$.

\subsection{Test Vehicle of Resistance Measurement}

Kelvin structures were designed in chips to perform EM tests in Figure 1. Kelvin structures 1 3 were located at the corners of the top die, and a 3D image was observed by the 3D X-ray machine (Carl Zeiss Co. Ltd., Oberkochen, Germany), as shown in Figure 3. The Kelvin structure was composed of three $\mathrm{Cu}-\mathrm{Cu}$ bumps, named $\mathrm{A}, \mathrm{B}$, and $\mathrm{C}$, and RDLs. Current was applied by a power supply and the electron flow is marked by red arrows, so Kelvin bumps A and B were under high current stressing during the EM test. However, only the resistance of Kelvin bump B could be measured.

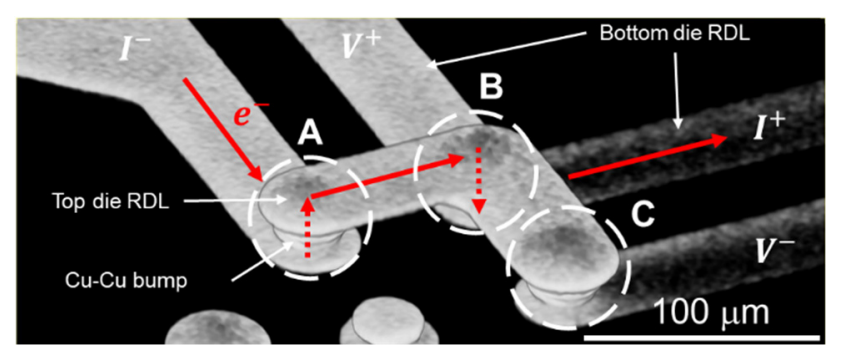

Figure 3. Nondestructive observation of Kelvin bumps. The resistance of the corner bump, named Kelvin bump B, can be measured. Kelvin bump A is under the same current stress during the EM test. Kelvin bump C connects with the $V^{-}$probe pad.

\subsection{Electromigration Test}

The diameter of the bonding interface was $30 \mu \mathrm{m}$, and that of the PSV opening was $14 \mu \mathrm{m}$. The pitch of $\mathrm{Cu}-\mathrm{Cu}$ bumps was $80 \mu \mathrm{m}$. The height of $\mathrm{Cu}-\mathrm{Cu}$ bumps was $14 \mu \mathrm{m}$. The width of the RDL was $45 \mu \mathrm{m}$, and the thickness was $3 \mu \mathrm{m}$. However, the actual dimension mentioned above might vary slightly because of the sample fabrication processes. The current of the EM test was $1.5 \mathrm{~A}$, and the chip was put on a hotplate (Yotec Instruments CO., LTD, Hsinchu City, Taiwan) at $150{ }^{\circ} \mathrm{C}$. The average current density at the bonding interface was $2.0 \times 10^{5} \mathrm{~A} / \mathrm{cm}^{2}$, and at the PSV opening, it was $9.8 \times 10^{5} \mathrm{~A} / \mathrm{cm}^{2}$. In the 
$\mathrm{RDL}$, the average current density was $1.1 \times 10^{6} \mathrm{~A} / \mathrm{cm}^{2}$. Thus, EM damages were expected to occur faster near the PSV opening and RDLs.

As Joule heating occurred significantly during EM tests [38], the actual temperature was measured through the method of the temperature coefficient of resistance (TCR). The measured temperature was different slightly from chip to chip, and the maximum value due to Joule heating was close to $50{ }^{\circ} \mathrm{C}$. The resistance of Kelvin bump B was recorded every $30 \mathrm{~s}$ during the EM test, and the criteria of EM failure were defined as $20 \%$ resistance change.

The microstructure of EM damages in Kelvin bumps was observed by the nondestructive observation of 3D X-rays (Carl Zeiss Co. Ltd., Oberkochen, Germany), and the destructive observation of Scanning electron microscope (SEM) and dual-beam focused ion beam (DB-FIB) (Field Electron and Ion Company, Hillsboro, Oregon, USA). A model of a single microbump was made to carry out FEA. The current density distribution could determine the current crowding effect. The distribution of tensile stress along the $\mathrm{z}$-axis could confirm the required bonding strength to avoid an open-circuit. Three chips of each bonding condition were fabricated without UF dispensing to perform the pull test, so the average bonding strength of each $\mathrm{Cu}-\mathrm{Cu}$ bump could be measured. A table listing the pull test of bonding strength is shown later.

\section{Results and Discussion}

3.1. As-Prepared Sample

Cross-sectional images of the microstructure of bonding conditions at $300{ }^{\circ} \mathrm{C} / 90 \mathrm{MPa} /$ $30 \mathrm{~s}$ and at $300{ }^{\circ} \mathrm{C} / 31 \mathrm{MPa} / 10 \mathrm{~s}$ are shown in Figure $2 \mathrm{a}-\mathrm{d}$, respectively. The electron images of Figure 2a,c show the void-free bonding interface. The ion images of Figure 2b, d show the microstructure of $\mathrm{Cu}$ grains. Due to the high bonding temperature and pressure, even for such a short bonding time, recrystallization of nt-Cu columnar grains occurred during the bonding process. However, $\mathrm{Cu}$ grains did not have enough time for grain growth, and the bonding interface was straight and clear across the $\mathrm{Cu}-\mathrm{Cu}$ bumps. More residual nt- $\mathrm{Cu}$ columnar grains are shown in Figure $2 \mathrm{~d}$ because of the lower bonding pressure and time.

\subsection{Electromigration Tests}

The resistance change during the EM test is shown in Figure 4. The EM lifetime of the bonding condition at $90 \mathrm{MPa} / 30 \mathrm{~s}$ was at least longer than $3500 \mathrm{~h}$, while that of the bonding condition at $31 \mathrm{MPa} / 10 \mathrm{~s}$ was only $170 \mathrm{~h}$. The profiles of resistance change of $90 \mathrm{MPa} / 30 \mathrm{~s}$ started from a steady increase, and then increased dramatically after it reached $10 \%$. This phenomenon is similar to the EM of damascene $\mathrm{Cu}$ interconnects [28]. In the early part of the resistance steady increase, voids form at the bonding interface and continuously increase. Once the void reaches the critical dimension, resistance will increase abruptly [39]. For the EM of solder bumps, the same issue of the change in resistance profile has been discussed. It is because current crowding enhances the growth rate of pancake-type voids below the contact interface, but the resistance does not increase abruptly before the open circuit [40]. Below, the EM failure modes of $\mathrm{Cu}-\mathrm{Cu}$ bumps are discussed.

\subsection{EM Failure at the Bonding Interface}

The cross-sectional images of $31 \mathrm{MPa} / 10$ s_K1 bumps are shown in Figure 5. Many tiny voids are found to be located at the PSV openings, which are indicated by the white arrows in the electron images of Figure 5a,b, in Kelvin bumps A and B, respectively. As vacancies cannot pass through the TiW layers [41], they accumulate to form voids on the TiW layers. According to a previous study of solder bumps [40], the sites of void formation are strongly related to current crowding, so the voids in Figure 5a,b are located at the corners between the PSV opening and RDL. 


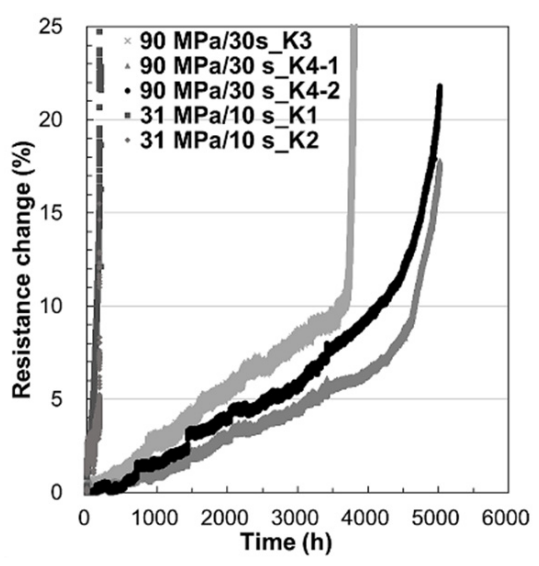

Figure 4. The lifetime of EM test. For the bonding condition $300{ }^{\circ} \mathrm{C} / 90 \mathrm{MPa} / 30 \mathrm{~s}$, the lifetime is longer than $3500 \mathrm{~h}$. For the bonding condition $300^{\circ} \mathrm{C} / 31 \mathrm{MPa} / 10 \mathrm{~s}$, the lifetime is longer than $170 \mathrm{~h}$.

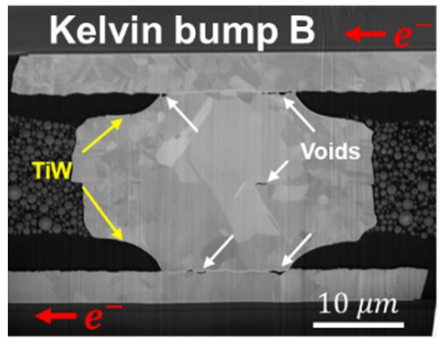

(a)

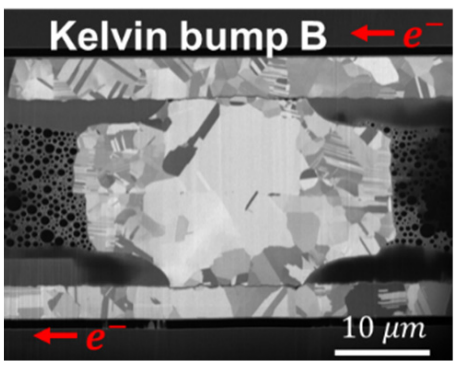

(c)

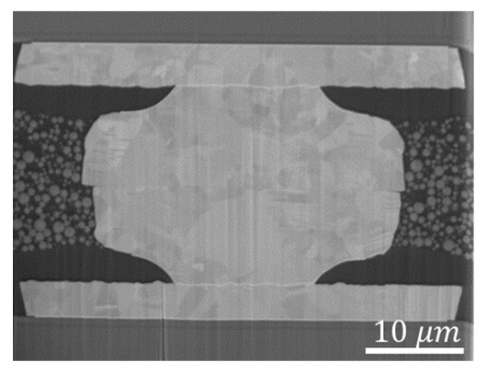

(e)

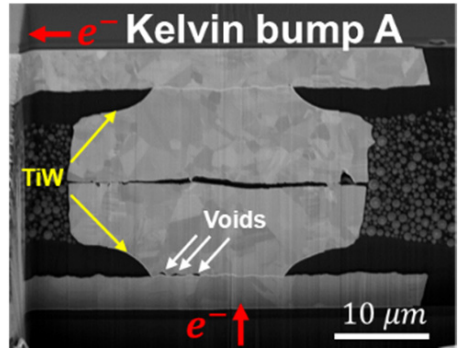

(b)

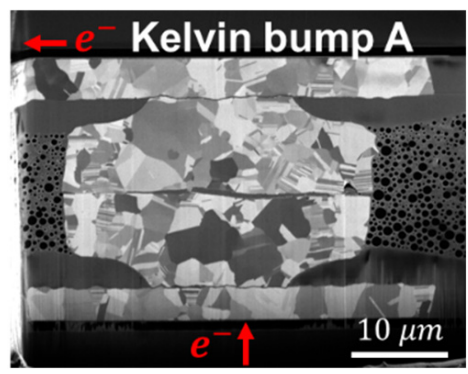

(d)

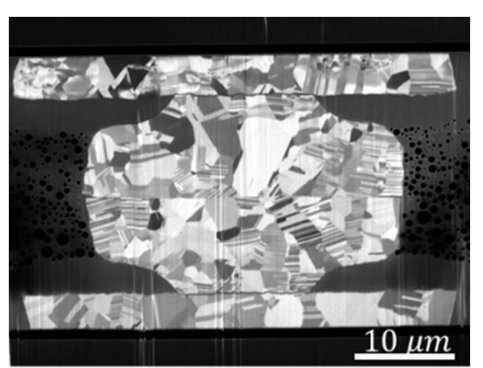

(f)

Figure 5. Destructive observation of the $31 \mathrm{MPa} / 10 \mathrm{~s} \_\mathrm{K} 1$ bumps. (a,b) Electron images of Kelvin bumps B and A, respectively. Voids are observed at the sites of current crowding. The voids form at the side of electron current passing through the TiW adhesion layer. In addition, the crack at the bonding interface of Kelvin bump A has caused an open circuit. (c,d) Ion images of Kelvin bumps B and A, respectively. In Kelvin bump B, grain growth across the bonding interface might be caused by the significant Joule heating before the open circuit of Kelvin bump A. (e,f) Electron image and ion image of a dummy bump, respectively. 
In Figure 5a, a void in the middle of the bonding interface of Kelvin bump B may be caused by grain growth to eliminate the bonding interface. As the as-bonded bonding interface is similar to a grain boundary with a high vacancy concentration, the vacancies might congregate to form a void, and the void might undergo ripening [42,43]. The big grains are shown in Figure 5c. A large grain has grown across the center of the bonding interface, and some small grains are separated at the two sides of the $\mathrm{Cu}-\mathrm{Cu}$ bump.

In Figure $5 b, d$, a large crack is shown along the bonding interface, so the circuit of the Kelvin bump is open. Figure 5e,f show the electron image and ion image of the dummy bump, respectively. The dummy bump does not undergo high current stressing but is located in the same chip and on the hotplate for the same time. There is no void in Figure 5e. The bonding interface maintains a straight line in Figure 5f, and many nt-Cu columnar grains remain. Compared with the as-fabricated $\mathrm{Cu}-\mathrm{Cu}$ bump in Figure $2 \mathrm{~d}$, small recrystallization grains grow during the EM test. However, the grain size of Figure $5 \mathrm{f}$ is smaller than that of Figure 5c,d because of the lack of Joule heating in the EM test.

\subsection{EM Failure at the Passivation (PSV) Opening}

To realize voids distribution of the EM test, the $\mathrm{Cu}-\mathrm{Cu}$ bump of $90 \mathrm{MPa} / 30 \mathrm{~s} \_\mathrm{K} 3$ was observed by 3D X-ray tomography, which is shown in Figure 6. The resolution of the 3D $\mathrm{X}$-ray was $0.8 \mu \mathrm{m}$. The final resistance change of $90 \mathrm{MPa} / 30 \mathrm{~s} \_\mathrm{K} 3$ reached $115 \%$, so the void size was large enough to be recognized. The computed tomography (CT) of the top die RDL is shown in Figure 6a. Due to the electron current direction and the TiW layer, voids can be recognized easily at the top die RDL of Kelvin bump A. Most of the voids distributed at the side close to Kelvin bump B of the PSV opening, and some voids were at the opposite PSV opening. There was no void at the top die RDL of Kelvin bump B.

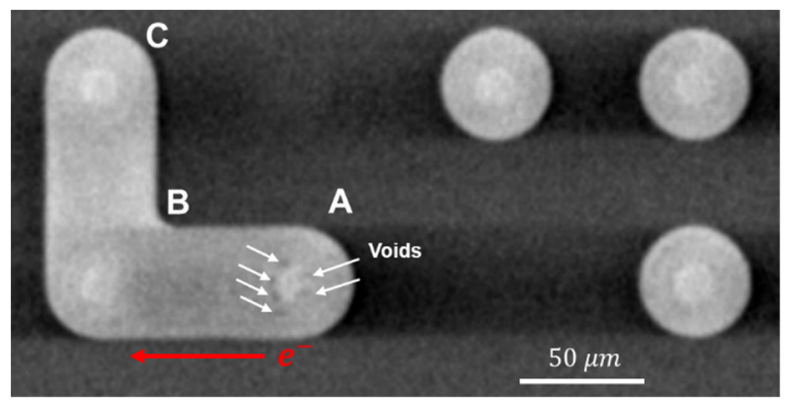

(a)

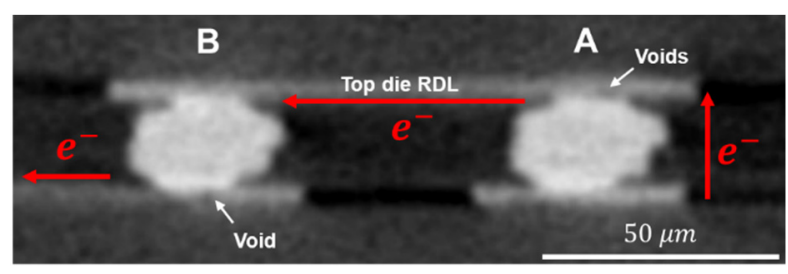

(b)

Figure 6. Nondestructive observation of $90 \mathrm{MPa} / 30$ s_K3 bumps. (a) Computed tomography of the top die RDL. The voids form at the top die RDL of Kelvin bump A. (b) Computed tomography of the cross-section along the current direction in Kelvin bumps. The voids are observed at the top die RDL of Kelvin bump A and at the bottom die RDL of Kelvin bump B.

The CT of the cross-section along the electron current flow direction in Kelvin bumps is shown in Figure 6b. The void of Kelvin bump A was located in the top die RDL, and the void of Kelvin bump B was located in the bottom die RDL. Due to the limitation of the 3D X-ray resolution, if the void size is too small in $\mathrm{CT}$, it is difficult to recognize. The left part of the voids in the top die RDL of Kelvin bump A in Figure 6a is clear, but they are ambiguous in Figure $6 \mathrm{~b}$. Therefore, the void shape must be a plane-shape in the top die 
RDL and close to the PSV opening. On the contrary, the right-hand-side part of the voids in the top die RDL of Kelvin bump A tend to be a long-shaped void across the height of the RDL. It can also be proven in Figure 7 of destructive observation, as shown below.

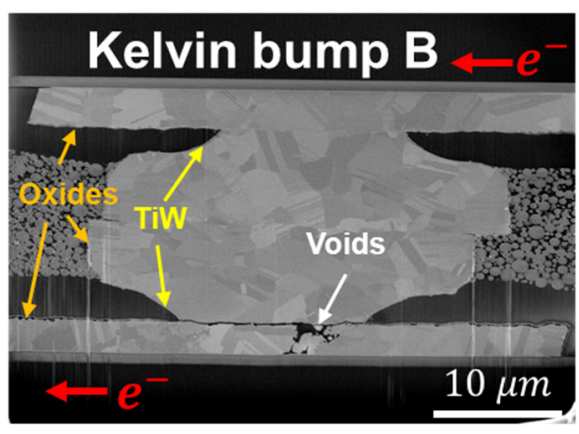

(a)

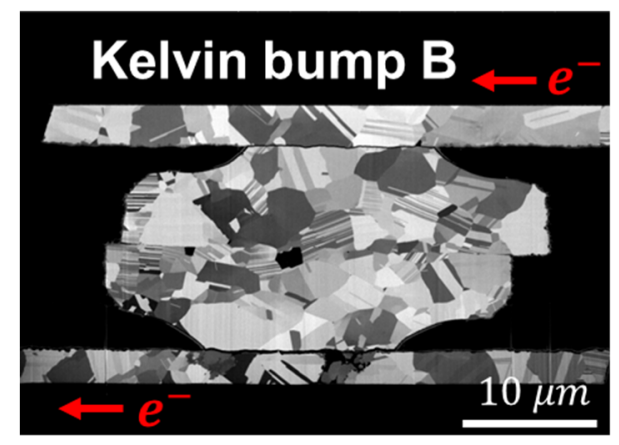

(c)

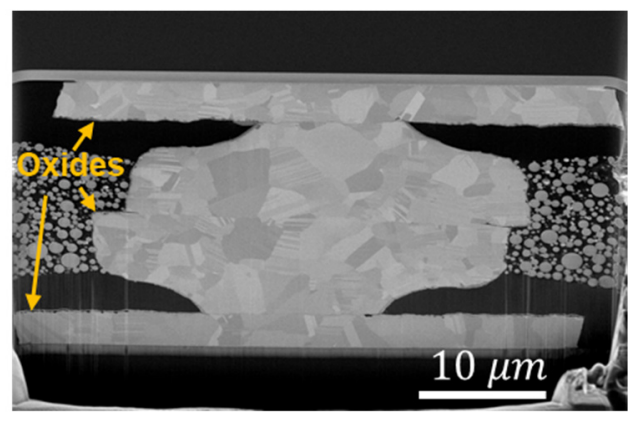

(e)

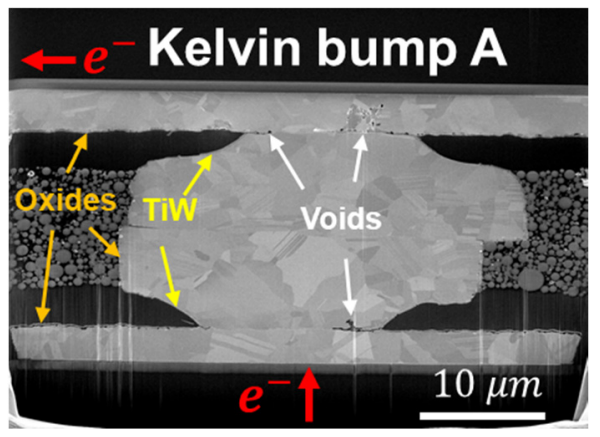

(b)

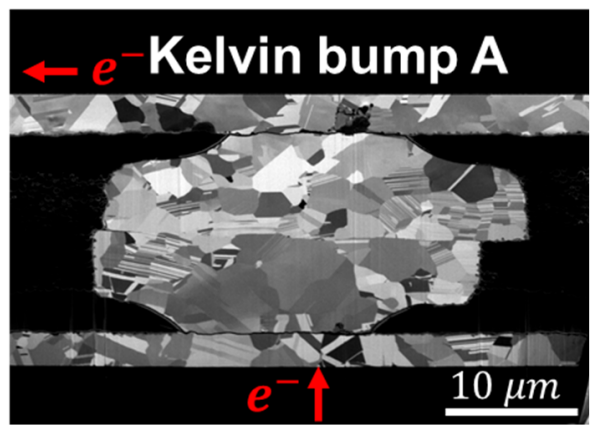

(d)

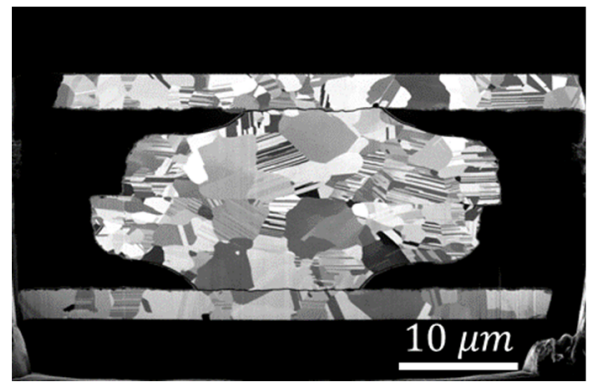

(f)

Figure 7. Destructive observation of $90 \mathrm{MPa} / 30$ s_K3 bumps. (a,b) Electron images of Kelvin bumps B and A, respectively. Voids are located at the top die RDL of Kelvin bump A and the bottom die RDL of Kelvin bump B, which is the same as the nondestructive observation results. The voids at the lower part of $\mathrm{Cu}-\mathrm{Cu}$ bump A can be seen in (b). The voids form at the side of electron current passing through the TiW layer. (c,d) Ion images of Kelvin bumps B and A, respectively. The voids caused by the EM are along the grain boundary and TiW layer at the PSV opening. (e,f) Electron image and ion image of dummy bumps, respectively. Copper oxide can be found at the surface of $\mathrm{Cu}-\mathrm{Cu}$ bumps and RDLs.

Figure 7 shows the electron and ion cross-sectional images of the same Kelvin bump in Figure 6, but a more precise microstructure of the cross-sectional images can be observed in Figure 7. In Figure 7a, a narrow void is shown under the TiW layer at the bottom of Kelvin bump B, which may have caused the open circuit of the Kelvin structure, and the resistance change is $115 \%$ after $4035 \mathrm{~h}$ of EM stressing time. The Kelvin 3 structure is shown at the lower left corner of the chip, which is shown in Figure 1. Owing to such a long EM stressing time and also close to the edge of the top die, there is a layer of oxide covering the surface of the Kelvin bump and dummy bump, which is shown in Figure 7a,b,e. 
As $\mathrm{Cu}$ oxide has a poor adhesion to $\mathrm{Cu}$, there are some voids between the oxide and $\mathrm{Cu}$, as shown in Figure 7e of the dummy bump. More serious void formation in Figure 7a,b might be caused by EM in driving $\mathrm{Cu}$ surface diffusion, and Joule heating enhances the oxidation rate. However, the oxide thickness does not show a big difference between the Kelvin bump and dummy bump. Moreover, the voids of Kelvin bumps between the oxide and the bottom die RDLs are more serious than those of the top die RDL. It might be the short-length effect in EM [28].

During the EM test, the $\mathrm{Cu}$ atomic flux $\left(J_{E M}\right)$ was taken to be [44-47]:

$$
J_{E M}=C \frac{D}{k T} F_{e}+C \frac{D}{k T} F_{b}=C \frac{D}{k T}\left(Z^{*} e \rho j-\frac{\Delta \sigma \Omega}{\Delta x}\right)
$$

where $C$ is the concentration of $\mathrm{Cu}, \mathrm{D}$ is the diffusivity, $k$ is the Boltzmann constant, $T$ is the temperature during the EM test, $F_{e}$ is the electrical force, $F_{b}$ is the mechanical force caused by a stress gradient, $Z^{*}$ is the effective charge number of EM, $e$ is the charge of an electron, $\rho$ is the resistivity of $\mathrm{Cu}, j$ is the current density, $\Delta \sigma$ is the EM-induced back stress, $\Omega$ is the atomic volume, and $\Delta x$ is the length of metal line.

If $J_{E M}=0$, which means that $F_{e}=F_{b}$, the critical product $(j \Delta x)_{c}$ can be derived, which has been called the short-length effect in $\mathrm{Al}$ and $\mathrm{Cu}$ stripes [48,49]. The equation of the critical product of current density $(j)$ and length of metal $(\Delta x)$ is [50]:

$$
(j \Delta x)_{c}=\frac{\Delta \sigma \Omega}{Z^{*} e \rho}
$$

If $j \Delta x$ is larger than $(j \Delta x)_{c}, E M$ damage can occur. In Figure 7 , the thickness of the top die RDL is $3 \mu \mathrm{m}$ and that of the bottom die RDL is $2.4 \mu \mathrm{m}$, which makes the current density of the bottom die RDL $\left(j_{\text {bottom } R D L}\right)$ larger than that of the top die RDL $\left(j_{\text {top } R D L}\right)$. The length of the RDL can be found in Figure 1, Figure 3, and Figure 6. The length of the top die RDL $\left(\Delta x_{t o p} R D L\right)$ under current stressing is about $125 \mu \mathrm{m}$, but that of the bottom die RDL $\left(\Delta x_{\text {bottom } R D L}\right)$ is much longer in order to connect the probe pads on the bottom die. Therefore, the product of $(j \Delta x)_{\text {bottom } R D L}$ is larger than that of $(j \Delta x)_{\text {top } R D L^{\prime}}$ and the damage of EM is more serious in the bottom die RDL. Of course, higher current density leads to severe Joule heating, but the scale of the RDL and bump and the high thermal conductivity of $\mathrm{Cu}$ and $\mathrm{Si}$ can reduce the variation in temperature due to Joule heating.

\subsection{Much Slower EM Damage in Well-Bonded Samples}

The Kelvin bumps of $90 \mathrm{MPa} / 30$ s_K4 were the other sample under the long-time (5022 h) EM test. The resistance changes were $17.7 \%$ and $21.7 \%$ for K4-1 and K4-2, respectively. The cross-sectional images of $90 \mathrm{MPa} / 30 \mathrm{~s} \_\mathrm{K} 4$ are shown in Figure 8. Voids tended to form at the surface of the RDL, between TiW and the RDL, and between TiW and PSV opening. These failure modes were similar to those for $90 \mathrm{MPa} / 30 \mathrm{~s}$ _K3. However, in Figure 1, the site of K4 is shown to be located away from the edge of the top die, so there was no oxidation on the $\mathrm{Cu}$ surface of $\mathrm{K} 4$. In addition, a void formed in the bottom die RDL far from the $\mathrm{Cu}-\mathrm{Cu}$ bump, which is located on the lower left side of Figure 8a.

Another phenomenon caused by EM is the small hillock that formed at the bottom die RDL of K4-1 in Figure 8a. It was the site of electron current flow into the PSV opening, and the TiW layer stopped the $\mathrm{Cu}$ atomic flux so that the accumulation of $\mathrm{Cu}$ atoms occurred and formed a hillock on the RDL surface. This phenomenon was similar to the EM of metal strips, in which hillocks formed at the anode [51]. Due to the long EM testing time, $\mathrm{Cu}$ grains had sufficient time to grow in $\mathrm{Cu}-\mathrm{Cu}$ bumps. Therefore, in Figures 7 and $8 \mathrm{c}, \mathrm{d}, \mathrm{f}$, the bonding interfaces changed into zig-zag-type grain boundaries [52], and there were much fewer fine grains than those of the as-fabricated $\mathrm{Cu}-\mathrm{Cu}$ bumps in Figure $2 \mathrm{~b}$. 


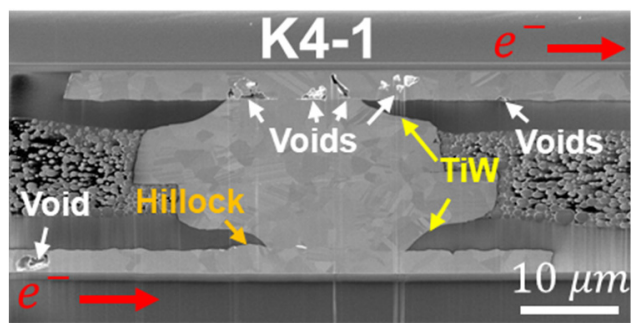

(a)

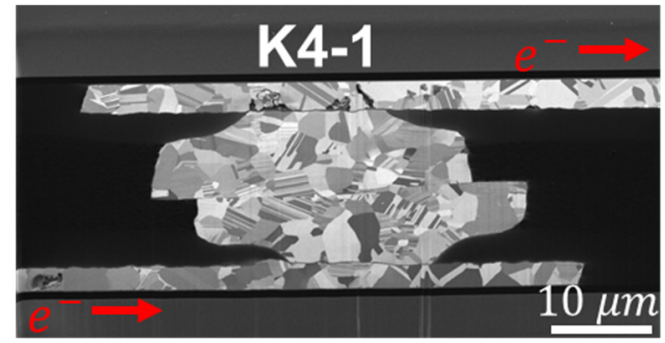

(c)

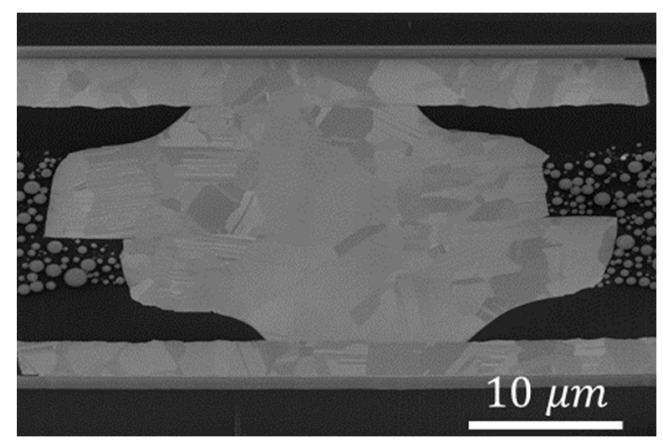

(e)

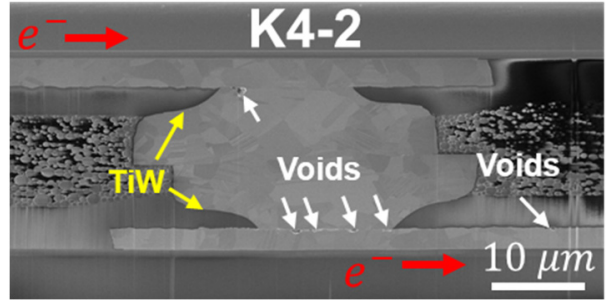

(b)

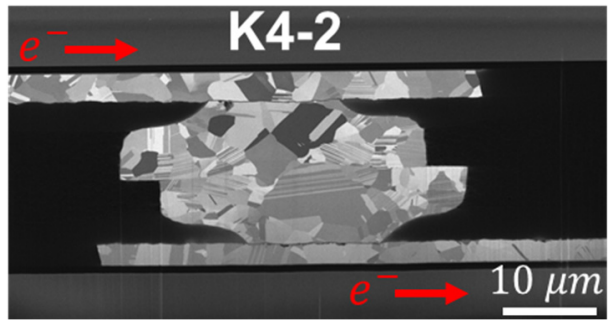

(d)

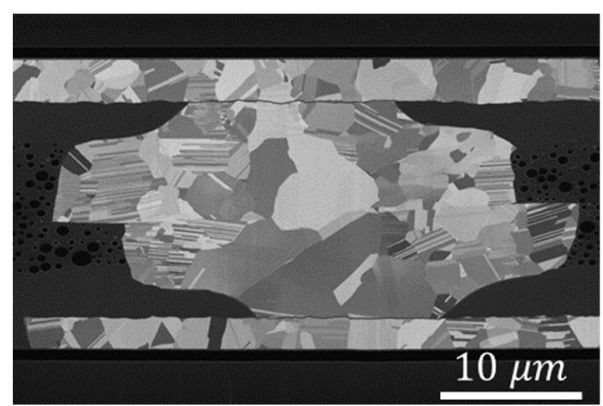

(f)

Figure 8. Destructive observation of $90 \mathrm{MPa} / 30$ s_K4 bumps. (a,b) Electron images of K4-1 and K4-2 bumps, respectively. Voids are observed at the sites of current crowding. The voids are located at the side of electron current passing through the TiW layer. Additionally, voids form in RDLs far from Cu-Cu bumps. (c,d) Ion images of K4-1 and K4-2 bumps, respectively. The voids caused by EM are located along the grain boundary and TiW layer at the PSV opening. (e,f) Electron image and ion image of dummy bumps, respectively. No $\mathrm{Cu}$ oxide at the surface of $\mathrm{Cu}-\mathrm{Cu}$ bumps and RDL appeared during EM test.

\subsection{Finite Element Analysis of EM Tests}

In order to realize the current crowding effect and stress distribution during the EM test, FEA was adopted and is depicted in Figure 9, where the 3D model is shown in Figure 9a. The 1.5 A current was applied, and the cross-section of the $\mathrm{Cu}-\mathrm{Cu}$ bump is shown in Figure 9b. Current crowding was observed at the edge of PSV opening, which is marked by red circles. The top view of the PSV opening is shown in Figure 9c. The maximum current density was $3.4 \times 10^{6} \mathrm{~A} / \mathrm{cm}^{2}$, and the shape of the current crowding area was crescent-like. This implies that the void distribution of the PSV opening or RDL was located at the edge of the contact area between the $\mathrm{Cu}-\mathrm{Cu}$ bump and RDL, and the actual result is shown in Figure 6a, which matched the current crowding area of the FEA result. Figure $9 \mathrm{~d}$ shows the current density distribution at the bonding interface. The maximum value of current density was $4.6 \times 10^{5} \mathrm{~A} / \mathrm{cm}^{2}$, so EM will occur slowly. 


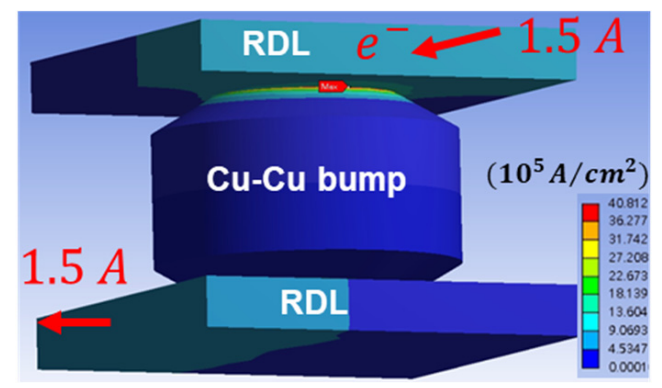

(a)

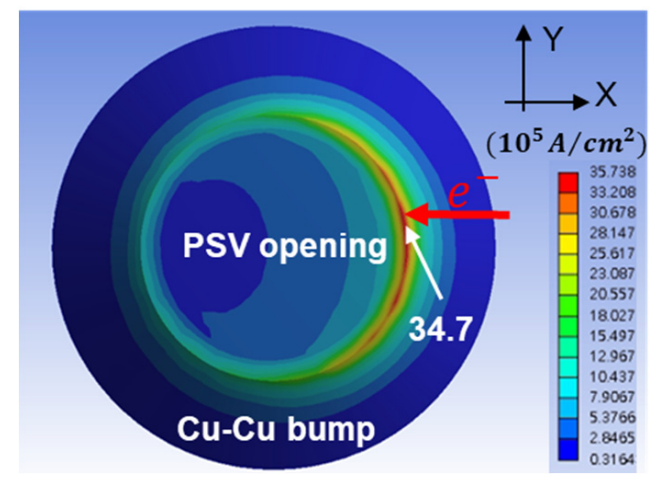

(c)

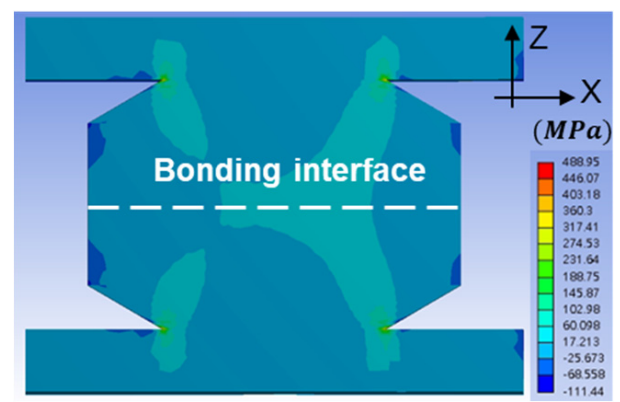

(e)

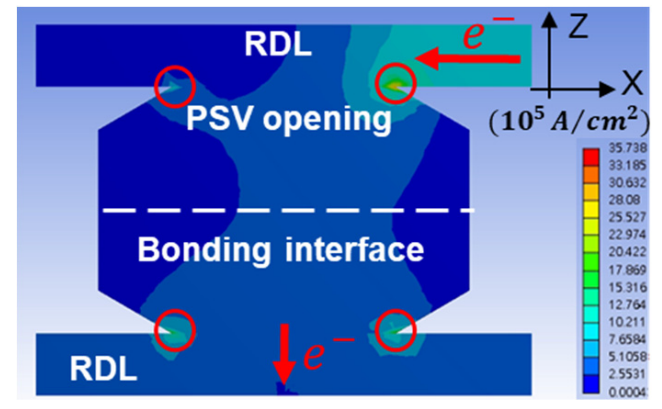

(b)

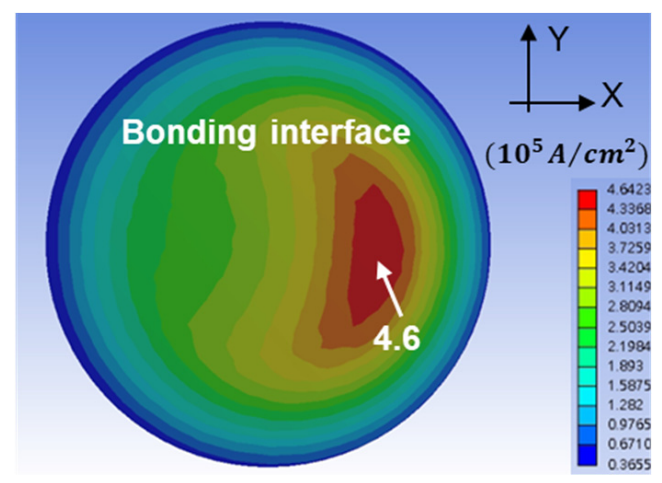

(d)

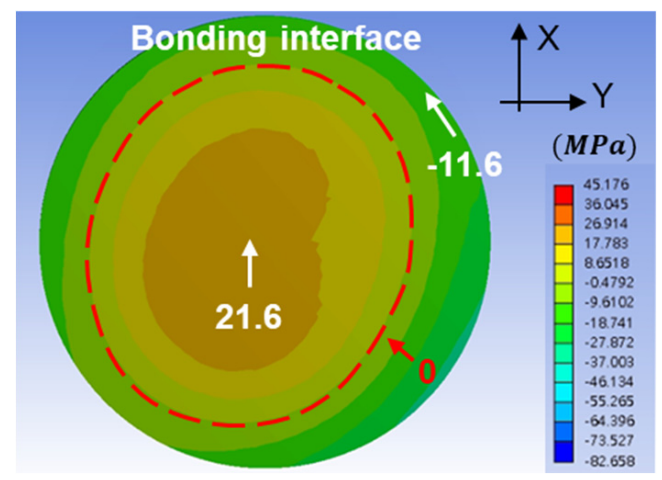

(f)

Figure 9. The FEA results of current density distribution and stress distribution. (a) The 3D model with electron current direction of single $\mathrm{Cu}-\mathrm{Cu}$ bump. (b) The current density distribution of the cross-section of a Cu-Cu bond. Current crowding is found at the PSV opening, which is marked by red circles. (c) The current density distribution at the top die PSV opening. (d) The current density distribution at the bonding interface. The maximum current density is $4.6 \times 10^{5} \mathrm{~A} / \mathrm{cm}^{2}$. (e) The distribution of stress along the z-axis at the cross-section of the $\mathrm{Cu}-\mathrm{Cu}$ bump. (f) The distribution of stress along the z-axis at the bonding interface. The maximum tensile stress during the EM test at the bonding interface is $21.6 \mathrm{MPa}$.

As the circuit of Kelvin bump A of $31 \mathrm{MPa} / 10 s_{-} \mathrm{K} 1$ showed an open circuit during the EM test in Figure $5 b$, the tensile stress distribution at $200{ }^{\circ} \mathrm{C}$ was of interest and is shown in Figure 9e. Tensile stress along the z-axis was thought to be the main reason for allowing the $\mathrm{Cu}-\mathrm{Cu}$ bump to open at the bonding interface. In Figure 9e,f, both sides of the model were set as mirror images to simulate the site of the chip corner, so that the tensile stress distribution is not symmetrical in the $\mathrm{Cu}-\mathrm{Cu}$ bump. To further emphasize the tensile stress distribution on the bonding interface, Figure $9 \mathrm{f}$ shows the tensile stress at the bonding interface. The maximum tensile stress of $21.6 \mathrm{MPa}$ was close to the center of the bonding interface. Interestingly, the edge of the bonding interface was under compressive stress, and the maximum compressive stress was $11.6 \mathrm{MPa}$. The red dashed line is the zero-stress 
line along the $z$-axis. Therefore, the bonding strength should be larger than $21.6 \mathrm{MPa}$ in order to sustain the $\mathrm{Cu}-\mathrm{Cu}$ bump structure during the EM test.

Bonding strength was measured by the pull test, as given in Table 1 , and the fracture mode is shown in Figure 10. The bonding strength was calculated by the pull force divided by the total bonding area. The total bonding area equaled a single bonding interface area multiplied by 4548 bumps, and the value was about $3.2 \mathrm{~mm}^{2}$. The bonding strength of bonding conditions $300{ }^{\circ} \mathrm{C} / 90 \mathrm{MPa} / 30 \mathrm{~s}$ was $50.86 \pm 3.12 \mathrm{MPa}$, and that of $300{ }^{\circ} \mathrm{C} /$ $31 \mathrm{MPa} / 10 \mathrm{~s}$ was $5.25 \pm 0.34 \mathrm{MPa}$. Thus, Kelvin bumps of $31 \mathrm{MPa} / 10 \mathrm{~s} \_\mathrm{K} 1$ had a high chance of becoming an open circuit. Figure 10 shows the fracture results of bonding conditions at $300{ }^{\circ} \mathrm{C} / 90 \mathrm{MPa} / 30 \mathrm{~s}$. The center of the array of bumps fractured at the bonding interface, so a ductile fracture surface is shown in Figure 10b. On the other hand, bumps around the corners and edges fractured at the PSV opening, and the ductile fracture at PSV opening is shown in Figure 10c. The white dashed line in Figure 10a shows the distribution of fracture modes in Figure 10b,c. The reason for this kind of distribution might be the process capability, such as chemical mechanical planarization and leveling of the bonding machine.

Table 1. Bonding strength of two bonding conditions.

\begin{tabular}{cc}
\hline Bonding Condition & Bonding Pressure (MPa) \\
\hline $300{ }^{\circ} \mathrm{C} / 90 \mathrm{MPa} / 30 \mathrm{~s}$ & $50.86 \pm 3.12$ \\
$300{ }^{\circ} \mathrm{C} / 31 \mathrm{MPa} / 10 \mathrm{~s}$ & $5.25 \pm 0.34$ \\
\hline
\end{tabular}

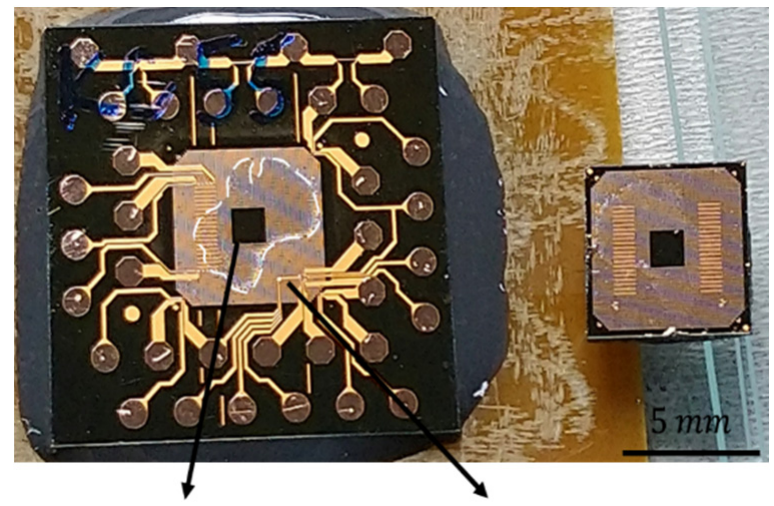

(a)

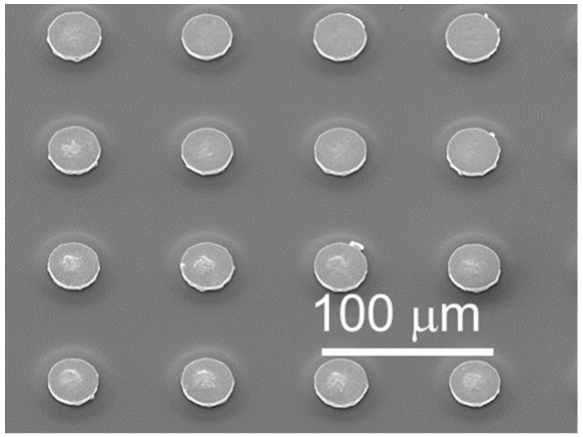

(b)

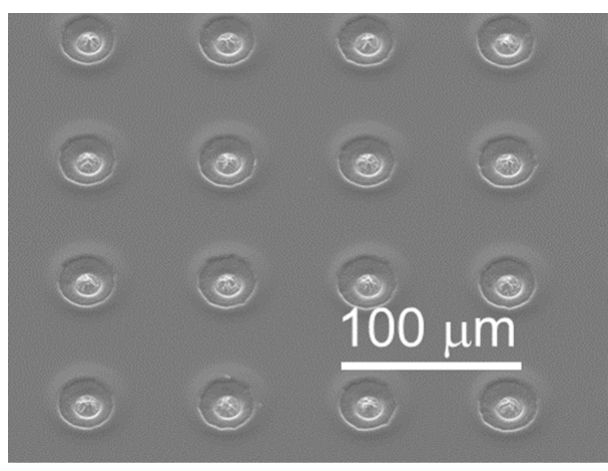

(c)

Figure 10. (a) The images of the chip after tensile test. The bonding condition is $300{ }^{\circ} \mathrm{C} / 90 \mathrm{MPa} / 30 \mathrm{~s}$. Two kinds of fracture modes are observed. (b) At the center area, fracture tended to form at the bonding interface. (c) At the edge of the bump array, fracture occurred at PSV openings. 


\subsection{EM Failure Mechanisms in $\mathrm{Cu}$-Cu Bonding}

Based on the experimental data above, the EM failure mechanisms of $\mathrm{Cu}-\mathrm{Cu}$ direct bonding are discussed below, and the relationships during the EM test among electron current, $\mathrm{Cu}$ atoms, vacancies, and TiW layers are illustrated in Figure 11. According to Reference [47], the surface diffusivity on $\mathrm{Cu}$ is about two orders of magnitude faster than that of grain boundary diffusivity at $200{ }^{\circ} \mathrm{C}$. Another research report showed that the interface of $\mathrm{Cu}$ and a surface coating layer is the other fast diffusion path. Therefore, in this study, surface diffusion, $\mathrm{Cu}$ /TiW interface diffusion, and grain boundary diffusion were the three main diffusion paths. The current density of the current crowding effect and RDLs was close to or higher than $10^{6} \mathrm{~A} / \mathrm{cm}^{2}$, so EM of $\mathrm{Cu}$ will occur at the edge of the PSV opening and RDLs, and only the grain boundaries at those two sites will participate in the EM. Thus, the grain size at the PSV opening and RDLs will influence the EM lifetime, and the interface of $\mathrm{Cu} / \mathrm{TiW}$ will lead to the void formation along the contact area of the $\mathrm{Cu}-\mathrm{Cu}$ bump and $\mathrm{Cu}$ RDLs. A previous research report showed that $\mathrm{Cu}$ atoms cannot diffuse through the TiW layer [41]. Therefore, $\mathrm{Cu}$ atom diffusion will be retarded and accumulate at the $\mathrm{Cu} / \mathrm{TiW}$ interface at the side of electron current flow in the TiW layer. On the other hand, vacancies will accumulate at the side of electron current flow out of the TiW layer, and will aggregate into voids.

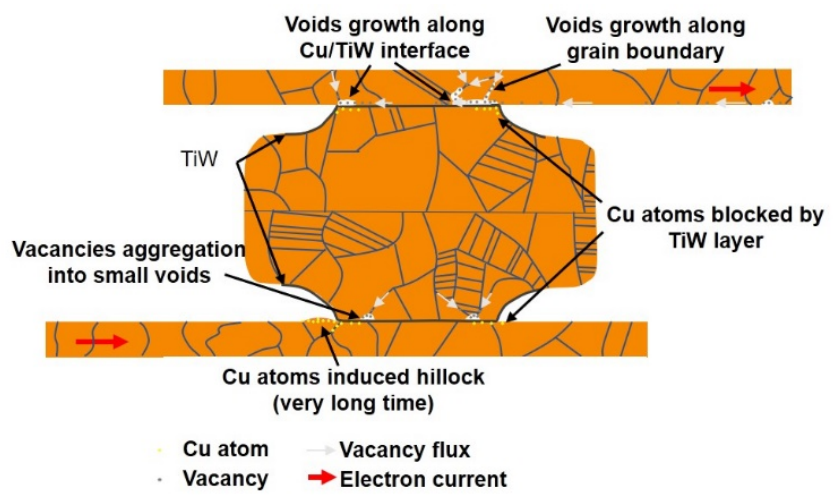

Figure 11. The relationships during the EM test among electron current direction, $\mathrm{Cu}$ atoms, vacancies, and TiW layers. The $\mathrm{Cu}$ atoms and vacancies are emphasized on the anode and cathode, respectively. The anode and cathode are defined by the electron current direction and the TiW layer. Due to those mechanisms, voids and hillock can be formed.

The critical product $\left((j \Delta x)_{c}\right)$ of Equation (2) is related to back stress $(\Delta \sigma)$. The back stress $(\Delta \sigma)$ can be introduced from the surrounding $\mathrm{Cu}$ atoms, confinement of TiW layers, PSV layers, and Si substrates, and the residual stress of electroplating and thermal annealing. However, the stress from the PBO confinement can be ignored for the soft material, and the residual stress can be relaxed during the long EM test time. Thus, the back stress is mainly caused by the surrounding $\mathrm{Cu}$ atoms and the confinement of TiW layers. Additionally, the $\mathrm{Cu}$ atomic flux of Equation (1) is related to the mechanical force induced by the back stress gradient. If the length $(\Delta x)$ of $\mathrm{Cu}$ circuits is longer, the influence of back stress on $\mathrm{Cu}$ EM will be smaller, so the void formation in Cu RDLs is more significant.

In the $\mathrm{Cu}$ RDLs, the PBO layer cannot restrict the Cu hillock formation beside the PSV opening. For an EM test time long enough for $\mathrm{Cu}$ atom accumulation, a hillock can be observed in Figure 8a; however, the dimension of RDLs, which is the sink of $\mathrm{Cu}$ atoms, is so large that the hillock is not obvious. On the contrary, the accumulation of $\mathrm{Cu}$ atoms in $\mathrm{Cu}-\mathrm{Cu}$ bumps is less for the short length effect, and the TiW layer can restrain any protrusion. Therefore, no hillock can be recognized in the anode of the $\mathrm{Cu}-\mathrm{Cu}$ bump. Combined with the effects of the diffusion paths, TiW layers, and critical products of the $\mathrm{Cu}-\mathrm{Cu}$ bump and RDLs, voids are observed at the site of current crowding, and in the RDL, which are depicted in Figure 11. 
Considering the $\mathrm{Cu}$ atomic diffusion paths and the bonding strength, three kinds of EM failure mode are shown in Figure 12. In Figure 12a, if the bonding strength is not strong enough, $\mathrm{Cu}-\mathrm{Cu}$ bumps have a high chance to fracture at the bonding interface. This is the early failure mode. Due to the short EM test time, voids at the PSV opening tend to be tiny and form at triple junctions of the grain boundary and $\mathrm{Cu} / \mathrm{TiW}$ interface.

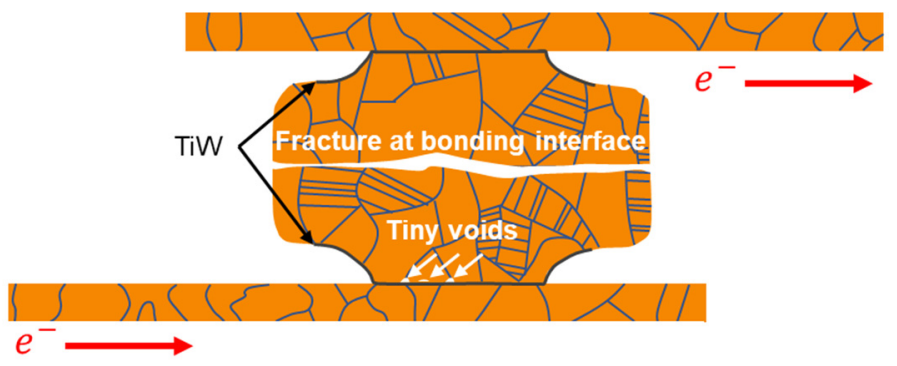

(a)

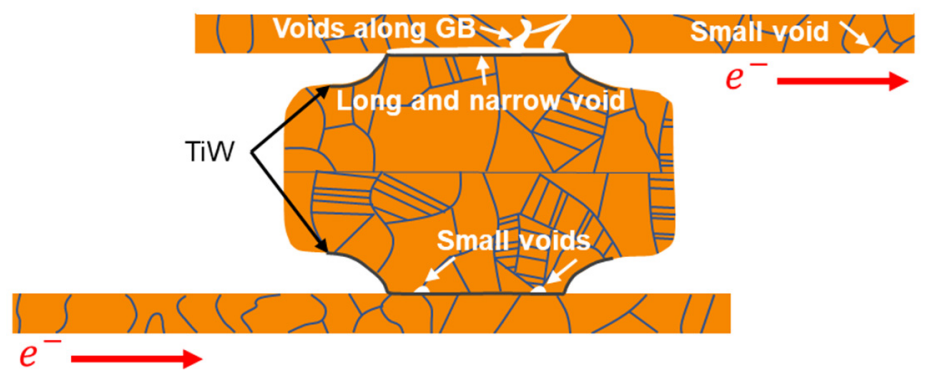

(b)

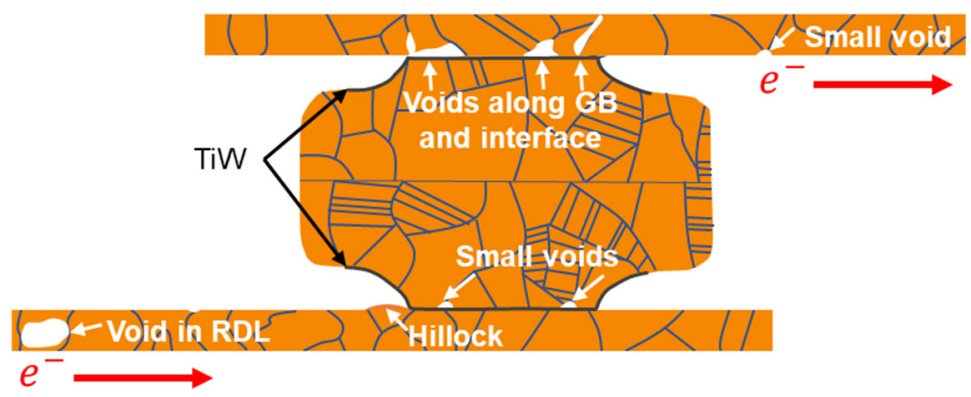

(c)

Figure 12. Three kinds of EM failure modes. (a) If the bonding strength cannot sustain the tensile stress during the EM test, fracture will occur at the bonding interface. Some tiny voids will form at the PSV opening due to the current crowding effect. This is a kind of early failure. The $\mathrm{Cu}-\mathrm{Cu}$ bumps of bonding condition $300{ }^{\circ} \mathrm{C} / 31 \mathrm{MPa} / 10 \mathrm{~s}$ with the bonding strength of about $5 \mathrm{MPa}$ will lead to this failure mode. (b) A long and narrow void at the contact area of the PSV opening and $\mathrm{RDL}$, which leads to an open circuit. Some voids grow along grain boundaries. Some small voids form in the $\mathrm{Cu}-\mathrm{Cu}$ bump at the bottom PSV opening and RDL surface. The $\mathrm{Cu}-\mathrm{Cu}$ bumps of the bonding condition $300{ }^{\circ} \mathrm{C} / 90 \mathrm{MPa} / 30 \mathrm{~s}$ with the bonding strength of about $50 \mathrm{MPa}$ have a chance to cause this failure mode. (c) Under an excellent bonding condition, some void formation may occur along grain boundaries and the interface in the RDL. Small voids form at the bottom PSV opening of the $\mathrm{Cu}-\mathrm{Cu}$ bump and RDL surface. In addition, void formation occurs randomly in the RDL far from the $\mathrm{Cu}-\mathrm{Cu}$ bump. The $\mathrm{Cu}-\mathrm{Cu}$ bumps of bonding condition $300{ }^{\circ} \mathrm{C} / 90 \mathrm{MPa} / 30 \mathrm{~s}$ with a bonding strength of approximately $50 \mathrm{MPa}$ have an opportunity to bring about this failure mode. 
In Figure $12 b$, a long and narrow void formed at the passivation contact area between the $\mathrm{Cu}-\mathrm{Cu}$ bump and RDL. When the current density or testing temperature is severe, this failure mode will become another killer of EM lifetime. Future work might involve optimizing the process to find an excellent adhesion layer to strengthen the interface of the $\mathrm{Cu}$ /adhesion layer [53]. Due to the short-length effect in EM, the void size in the RDL is larger than that in the $\mathrm{Cu}-\mathrm{Cu}$ bump. Some small voids might randomly form at the surface of the RDL for the long EM lifetime.

In Figure 12c, if voids at the contact area between the $\mathrm{Cu}-\mathrm{Cu}$ bump and RDL do not merge together, the EM lifetime will be much longer. Voids also tend to form at the grain boundary and surface, and the void size is influenced by the short-length effect. Besides, both void and hillock formation can occur under such a long EM lifetime, over $5000 \mathrm{~h}$.

\section{Summary}

Three kinds of EM failure mechanisms are summarized below. First, if the bonding strength is not strong enough, the circuit of the $\mathrm{Cu}-\mathrm{Cu}$ bump will open and lead to early failure. Second, if the bonding strength can sustain the tensile stress from the thermal mismatch of materials, EM-induced $\mathrm{Cu}$ diffusion and vacancy diffusion can last for a long time, until the growth of voids along the passivation interface leads to failure. Third, provided that no fracture occurs at the bonding interface, as well as at the passivation interface because of an excellent bonding process, a very long lifetime of electromigration, over $5000 \mathrm{~h}$, can be obtained, even though some small voids may have formed on the surface or interface in the bonding microstructure. However, if the diameter of the $\mathrm{Cu}-\mathrm{Cu}$ bump continuously shrinks below $10 \mu \mathrm{m}$, the current density must become larger and the EM of the $\mathrm{Cu}-\mathrm{Cu}$ bump will become a critical issue.

Author Contributions: Conceptualization, K.-C.S.; methodology, K.-C.S.; software, P.-N.H.; validation, K.-C.S., P.-N.H. and Y.-J.L.; formal analysis, K.-C.S., K.N.T. and C.C.; investigation, K.-C.S., P.-N.H. and Y.-J.L.; writing-original draft preparation, K.-C.S. and K.N.T.; writing-review and editing, K.-C.S., K.N.T. and C.C.; supervision, C.C.; project administration, C.C.; funding acquisition, C.C. All authors have read and agreed to the published version of the manuscript.

Funding: This research was financially funded by the Ministry of Science and Technology, Taiwan under contracts MOST-110-2634-F-009-027 and MOST-107-2221-E-009-007-MY3.

Institutional Review Board Statement: Not applicable.

Informed Consent Statement: Not applicable.

Data Availability Statement: Not applicable.

Conflicts of Interest: The authors declare no conflict of interest.

\section{References}

1. Chen, C.; Yu, D.; Chen, K.-N. Vertical interconnects of microbumps in 3D integration. MRS Bull. 2015, 40, 257-263. [CrossRef]

2. Kagawa, Y.; Fujii, N.; Aoyagi, K.; Kobayashi, Y.; Nishi, S.; Todaka, N.; Takeshita, S.; Taura, J.; Takahashi, H.; Nishimura, Y.; et al. Novel stacked CMOS image sensor with advanced $\mathrm{Cu} 2 \mathrm{Cu}$ hybrid bonding. In Proceedings of the 2016 IEEE International Electron Devices Meeting (IEDM), San Francisco, CA, USA, 3-7 December 2016; pp. 8.4.1-8.4.4.

3. Hu, C.C.; Chen, M.F.; Chiou, W.C.; Yu, D.C.H. 3D Multi-chip Integration with System on Integrated Chips (SoIC ${ }^{\mathrm{TM}}$ ). In Proceedings of the 2019 Symposium on VLSI Technology, Kyoto, Japan, 9-14 June 2019; pp. T20-T21.

4. Zeng, K.; Tu, K.N. Six cases of reliability study of Pb-free solder joints in electronic packaging technology. Mater. Sci. Eng. R Rep. 2002, 38, 55-105. [CrossRef]

5. Tu, K.N.; Gusak, A.M.; Li, M. Physics and materials challenges for lead-free solders. J. Appl. Phys. 2003, 93, 1335-1353. [CrossRef]

6. Tu, K.N. Reliability challenges in 3D IC packaging technology. Microelectron. Reliab. 2011, 51, 517-523. [CrossRef]

7. Shen, Y.-A.; Chen, C. Effect of Sn grain orientation on formation of Cu6Sn5 intermetallic compounds during electromigration. Scr. Mater. 2017, 128, 6-9. [CrossRef]

8. Liao, Y.-H.; Chen, C.-H.; Liang, C.-L.; Lin, K.-L.; Wu, A.T. A comprehensive study of electromigration in pure Sn: Effects on crystallinity, microstructure, and electrical property. Acta Mater. 2020, 200, 200-210. [CrossRef]

9. Kelly, M.B.; Niverty, S.; Chawla, N. Four dimensional (4D) microstructural evolution of Cu6Sn5 intermetallic and voids under electromigration in bi-crystal pure Sn solder joints. Acta Mater. 2020, 189, 118-128. [CrossRef] 
10. Mo, C.C.; Tran, D.P.; Juang, J.Y.; Chen, C. Effect of Intermetallic Compound Bridging on the Cracking Resistance of Sn2.3Ag Microbumps with Different UBM Structures under Thermal Cycling. Metals 2021, 11, 1065. [CrossRef]

11. Shigetou, A.; Itoh, T.; Sawada, K.; Suga, T. Bumpless Interconnect of 6- $\mu$ m-Pitch Cu Electrodes at Room Temperature. IEEE Trans. Adv. Packag. 2008, 31, 473-478. [CrossRef]

12. Made, R.I.; Gan, C.L.; Yan, L.; Kor, K.H.B.; Chia, H.L.; Pey, K.L.; Thompson, C.V. Experimental characterization and modeling of the mechanical properties of $\mathrm{Cu}-\mathrm{Cu}$ thermocompression bonds for three-dimensional integrated circuits. Acta Mater. 2012, 60, 578-587. [CrossRef]

13. Beyne, E.; Kim, S.; Peng, L.; Heylen, N.; Messemaeker, J.D.; Okudur, O.O.; Phommahaxay, A.; Kim, T.; Stucchi, M.; Velenis, D.; et al. Scalable, sub $2 \mu \mathrm{m}$ pitch, $\mathrm{Cu} / \mathrm{SiCN}$ to $\mathrm{Cu} / \mathrm{SiCN}$ hybrid wafer-to-wafer bonding technology. In Proceedings of the 2017 IEEE International Electron Devices Meeting (IEDM), San Francisco, CA, USA, 2-6 December 2017; pp. 32.4.1-32.4.4.

14. Panigrahy, A.K.; Chen, K.-N. Low Temperature Cu-Cu Bonding Technology in Three-Dimensional Integration: An Extensive Review. J. Electron. Packag. 2018, 140, 010801. [CrossRef]

15. Liu, C.-M.; Lin, H.-W.; Huang, Y.-S.; Chu, Y.-C.; Chen, C.; Lyu, D.-R.; Chen, K.-N.; Tu, K.-N. Low-temperature direct copper-tocopper bonding enabled by creep on (111) surfaces of nanotwinned Cu. Sci. Rep. 2015, 5, 9734. [CrossRef]

16. Kunimune, T.; Kuramoto, M.; Ogawa, S.; Sugahara, T.; Nagao, S.; Suganuma, K. Ultra thermal stability of LED die-attach achieved by pressureless Ag stress-migration bonding at low temperature. Acta Mater. 2015, 89, 133-140. [CrossRef]

17. He, R.; Fujino, M.; Yamauchi, A.; Wang, Y.; Suga, T. Combined Surface Activated Bonding Technique for Low-Temperature $\mathrm{Cu} /$ Dielectric Hybrid Bonding. ECS J. Solid State Sci. Technol. 2016, 5, P419-P424. [CrossRef]

18. Shie, K.-C.; Juang, J.-Y.; Chen, C. Instant Cu-to-Cu direct bonding enabled by <111>-oriented nanotwinned Cu bumps. Jpn. J. Appl. Phys. 2019, 59, SBBA03. [CrossRef]

19. Chang, S.-Y.; Chu, Y.-C.; Tu, K.N.; Chen, C. Effect of anisotropic grain growth on improving the bonding strength of <111> oriented nanotwinned copper films. Mater. Sci. Eng. A 2021, 804, 140754. [CrossRef]

20. Chou, T.C.; Huang, S.Y.; Chen, P.J.; Hu, H.W.; Liu, D.; Chang, C.W.; Ni, T.H.; Chen, C.J.; Lin, Y.M.; Chang, T.C.; et al. Electrical and Reliability Investigation of $\mathrm{Cu}$-to-Cu Bonding With Silver Passivation Layer in 3-D Integration. IEEE Trans. Compon. Packag. Manuf. Technol. 2021, 11, 36-42. [CrossRef]

21. Taïbi, R.; Cioccio, L.D.; Chappaz, C.; Francou, M.; Dechamp, J.; Larre, P.; Moreau, S.; Chapelon, L.; Fortunier, R. Investigation of stress induced voiding and electromigration phenomena on direct copper bonding interconnects for 3D integration. In Proceedings of the 2011 IEEE International Electron Devices Meeting (IEDM), Washington, DC, USA, 5-7 December 2011; pp. 6.5.1-6.5.4.

22. Moreau, S.; Fraczkiewicz, A.; Bouchu, D.; Bleuet, P.; Cloetens, P.; Silva, J.C.D.; Manzanarez, H.; Lorut, F.; Lhostis, S. Correlation Between Electromigration-Related Void Volumes and Time-to-Failure by High Resolution X-Ray Tomography and Modeling. IEEE Electron Device Lett. 2019, 40, 1808-1811. [CrossRef]

23. Tseng, I.H.; Hsu, P.-N.; Lu, T.-L.; Tu, K.N.; Chen, C. Electromigration failure mechanisms of $<111>$-oriented nanotwinned Cu redistribution lines with polyimide capping. Result. Phys. 2021, 24, 104154. [CrossRef]

24. Shie, K.C.; Hsu, P.N.; Li, Y.J.; Tu, K.N.; Lin, B.T.H.; Chang, C.C.; Chen, C. Electromigration and Temperature Cycling Tests of $\mathrm{Cu}-\mathrm{Cu}$ Joints Fabricated by Instant Copper Direct Bonding. In Proceedings of the 2021 IEEE 71st Electronic Components and Technology Conference (ECTC), San Diego, CA, USA, 1 June-4 July 2021; pp. 995-1000.

25. Moreau, S.; Beilliard, Y.; Coudrain, P.; Bouchu, D.; Cioccio, L.D.; Arnaud, L. Electromigration in hybrid bonding interconnects for 3-D IC impact of the diffusion barrier. In Proceedings of the 2015 IEEE 17th Electronics Packaging and Technology Conference (EPTC), Singapore, 2-4 December 2015; pp. 1-6.

26. Ho, P.S.; Kwok, T. Electromigration in metals. Rep. Prog. Phys. 1989, 52, 301-348. [CrossRef]

27. Ogawa, E.T.; Ki-Don, L.; Blaschke, V.A.; Ho, P.S. Electromigration reliability issues in dual-damascene Cu interconnections. IEEE Trans. Reliab. 2002, 51, 403-419. [CrossRef]

28. Li, B.; Sullivan, T.D.; Lee, T.C.; Badami, D. Reliability challenges for copper interconnects. Microelectron. Reliab. 2004, 44, 365-380. [CrossRef]

29. Hau-Riege, C.S. An introduction to Cu electromigration. Microelectron. Reliab. 2004, 44, 195-205. [CrossRef]

30. Tan, C.M.; Roy, A. Electromigration in ULSI interconnects. Mater. Sci. Eng. R Rep. 2007, 58, 1-75. [CrossRef]

31. Shie, K.-C.; Hsu, P.-N.; Li, Y.-J.; Tran, D.-P.; Chen, C. Failure Mechanisms of Cu-Cu Bumps under Thermal Cycling. Materials 2021, 14, 5522. [CrossRef]

32. Hsiao, H.-Y.; Liu, C.-M.; Lin, H.-w.; Liu, T.-C.; Lu, C.-L.; Huang, Y.-S.; Chen, C.; Tu, K.N. Unidirectional Growth of Microbumps on (111)-Oriented and Nanotwinned Copper. Science 2012, 336, 1007-1010. [CrossRef]

33. Liu, T.-C.; Liu, C.-M.; Hsiao, H.-Y.; Lu, J.-L.; Huang, Y.-S.; Chen, C. Fabrication and Characterization of (111)-Oriented and Nanotwinned Cu by Dc Electrodeposition. Cryst. Growth Des. 2012, 12, 5012-5016. [CrossRef]

34. Li, Y.-J.; Tu, K.-N.; Chen, C. Tensile Properties and Thermal Stability of Unidirectionally $<111>$ Oriented Nanotwinned and $<110>$ Oriented Microtwinned Copper. Materials 2020, 13, 1211. [CrossRef]

35. Cheng, H.-Y.; Tran, D.-P.; Tu, K.; Chen, C. Effect of deposition temperature on mechanical properties of nanotwinned Cu fabricated by rotary electroplating. Mater. Sci. Eng. A 2021, 811, 141065. [CrossRef]

36. Tran, D.-P.; Chen, K.-J.; Tu, K.; Chen, C.; Chen, Y.-T.; Chung, S. Electrodeposition of slanted nanotwinned Cu foils with high strength and ductility. Electrochim. Acta 2021, 389, 138640. [CrossRef] 
37. Hung, Y.-W.; Tran, D.-P.; Chen, C. Effect of Cu Ion Concentration on Microstructures and Mechanical Properties of Nanotwinned $\mathrm{Cu}$ Foils Fabricated by Rotary Electroplating. Nanomaterials 2021, 11, 2135. [CrossRef]

38. Tu, K.N.; Liu, Y.; Li, M. Effect of Joule heating and current crowding on electromigration in mobile technology. Appl. Phys. Rev. 2017, 4, 011101. [CrossRef]

39. He, J.; Suo, Z.; Marieb, T.N.; Maiz, J.A. Electromigration lifetime and critical void volume. Appl. Phys. Lett. 2004, 85, 4639. [CrossRef]

40. Yeh, E.C.C.; Choi, W.J.; Tu, K.N.; Elenius, P.; Balkan, H. Current-crowding-induced electromigration failure in flip chip solder joints. Appl. Phys. Lett. 2002, 80, 580-582. [CrossRef]

41. Hu, C.-K.; Rosenberg, R.; Lee, K.Y. Electromigration path in Cu thin-film lines. Appl. Phys. Lett. 1999, 74, 2945-2947. [CrossRef]

42. Rebhan, B.; Svoboda, J.; Panholzer, M. A thermodynamic study of voiding phenomena in Cu-Cu thermo-compression wafer bonding. Microsyst. Technol. 2017, 24, 815-822. [CrossRef]

43. Lu, T.-F.; Lai, T.-Y.; Chu, Y.Y.; Wu, Y.S. Effect of Nanotwin Boundary on the Cu-Cu Bonding. ECS J. Solid State Sci. Technol. 2021, 10, 074001. [CrossRef]

44. Herring, C. Diffusional Viscosity of a Polycrystalline Solid. J. Appl. Phys. 1950, 21, 437-445. [CrossRef]

45. Huntington, H.; Grone, A. Current-induced marker motion in gold wires. J. Phys. Chem. Solids 1961, 20, 76-87. [CrossRef]

46. Blech, I.A.; Herring, C. Stress generation by electromigration. Appl. Phys. Lett. 1976, 29, 131-133. [CrossRef]

47. Tu, K.N. Recent advances on electromigration in very-large-scale-integration of interconnects. J. Appl. Phys. 2003, 94, 5451-5473. [CrossRef]

48. Blech, I.A. Electromigration in thin aluminum films on titanium nitride. J. Appl. Phys. 1976, 47, 1203-1208. [CrossRef]

49. Frankovic, R.; Bernstein, G. Electromigration drift and threshold in $\mathrm{Cu}$ thin-film interconnects. IEEE Trans. Electron. Devices 1996, 43, 2233-2239. [CrossRef]

50. Tu, K.N. Electromigration in stressed thin films. Phys. Rev. B 1992, 45, 1409-1413. [CrossRef]

51. Liu, C.Y.; Chen, C.; Tu, K.N. Electromigration in $\mathrm{Sn}-\mathrm{Pb}$ solder strips as a function of alloy composition. J. Appl. Phys. 2000, 88, 5703-5709. [CrossRef]

52. Juang, J.-Y.; Lu, C.-L.; Li, Y.-J.; Hsu, P.-N.; Tsou, N.-T.; Tu, K.; Chen, C. A solid state process to obtain high mechanical strength in $\mathrm{Cu}$-to-Cu joints by surface creep on (111)-oriented nanotwins Cu. J. Mater. Res. Technol. 2021, 14, 719-730. [CrossRef]

53. Hu, C.-K.; Gignac, L.; Rosenberg, R.J.; Liniger, E.; Rubino, J.T.; Sambucetti, C.J.; Domenicucci, A.; Chen, X.; Stamper, A.K. Reduced electromigration of $\mathrm{Cu}$ wires by surface coating. Appl. Phys. Lett. 2002, 81, 1782-1784. [CrossRef] 